\title{
Indium mineralization in the Herberton Mineral Field, Northeast Queensland, Australia
}

\author{
AVISH KUMAR, IOAN SANISLAV AND PAUL DIRKS
}

James Cook University

Presenting Author: avish.kumar@my.jcu.edu.au

The demand for indium is continuously increasing as it is an important component of LCD, touchscreens, and solar panels. Indium is mainly sourced as a by-product from copper and zinc ore systems. Indium can occur in a variety of mineralized systems including VMS, porphyry, skarn, SEDEX, polymetallic veins, and magmatic-hydrothermal deposits. In the Herberton Mineral Field of Northeast Queensland, Australia, indium mineralization is related to magmatic-hydrothermal tin and polymetallic veins. The age of the mineralization is loosely constrained between 330 and 280 Ma, which was a period of intense magmatic and volcanic activity that affected the NE part of Australia. The largest indium bearing deposits in the region are the Baal Gammon and Isabel. The Baal Gammon deposit consists of a multistage tin and copper-zinc-indium mineralization. The tin mineralization is hosted almost exclusively by a granitic porphyry dyke that is overprinted by the copper-zinc-indium mineralization. The deposit has a total resource of $2.8 \mathrm{Mt}$ at $1 \%$ copper and $39 \mathrm{~g} / \mathrm{t}$ indium. The Isabel deposit consists of a series of lead-zinc polymetallic veins hosted by brecciated sediments along the contact with a quartz-feldspar porphyry dyke. The deposit has a total resource of $83 \mathrm{kt}$ at $15 \%$ zinc and $370 \mathrm{~g} / \mathrm{t}$ indium. The main host for indium is sphalerite, followed by chalcopyrite, and high indium concentrations were also found in stannite at the Baal Gammon deposit. No indium minerals have been identified so far. Although, sphalerite is the main host for indium, at the scale of the deposit, there is a very good correlation between indium and copper suggesting that the incorporation of indium into sphalerite is dependent on the availability of copper. Thermodynamic modelling suggests that the colligative properties of the mineralising fluids play an important role in concentrating and precipitating indium-rich sulphides while the physicochemical parameters deduce its mobility in the hydrothermal environment. 